\title{
Genetic selection for hoof health traits and cow mobility scores can accelerate the rate of genetic gain in producer- scored lameness in dairy cows
}

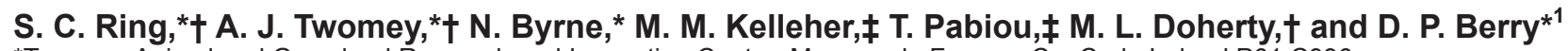 \\ *Teagasc, Animal and Grassland Research and Innovation Centre, Moorepark, Fermoy, Co. Cork, Ireland P61 C996 \\ †School of Veterinary Medicine, University College Dublin, Belfield, Dublin 4, Ireland D04 W6F6 \\ łlrish Cattle Breeding Federation, Highfield House, Bandon, Co. Cork, Ireland P72 X050
}

\begin{abstract}
Cattle breeding programs that strive to reduce the animal-level incidence of lameness are often hindered by the availability of informative phenotypes. As a result, indicator traits of lameness (i.e., hoof health and morphological conformation scores) can be used to improve the accuracy of selection and subsequent genetic gain. Therefore, the objectives of the present study were to estimate the variance components for hoof health traits using various phenotypes collected from a representative sample of Irish dairy cows. Also of interest to the present study was the genetic relationship between both hoof health traits and conformation traits with producer-scored lameness. Producer-recorded lameness events and linear conformation scores from 307,657 and 117,859 Irish dairy cows, respectively, were used. Data on hoof health (i.e., overgrown sole, white line disease, and sole hemorrhage), mobility scores, and body condition scores were also available from a research study on up to 11,282 Irish commercial dairy cows. Linear mixed models were used to quantify variance components for each trait and to estimate genetic correlations among traits. The estimated genetic parameters for hoof health traits in the present study were greater (i.e., heritability range: 0.005 to 0.27 ) than previously reported in dairy cows. With the exception of analyses that considered hoof health traits in repeatability models, little difference in estimated variance components existed among the various hoof-health phenotypes. Results also suggest that producer-recorded lameness is correlated with both hoof health (i.e., genetic correlation up to 0.48) and cow mobility (i.e., genetic correlation $=0.64$ ). Moreover, cows that genetically tend to have rear feet that appear more parallel when viewed from the rear are also genetically more predisposed to lameness (ge-
\end{abstract}

Received May 3, 2018.

Accepted July 24, 2018.

${ }^{1}$ Corresponding author: donagh.berry@teagasc.ie netic correlation $=0.39$ ) genetic correlations between lameness and other feet and leg type traits, as well as between lameness and frame type traits, were not different from zero. Results suggest that if the population breeding goal was to reduce lameness incidence, improve hoof health, or improve cow mobility, genetic selection for either of these traits should indirectly benefit the other traits. Results were used to quantify the genetic gains achievable for lameness when alternative phenotypes are available.

Key words: conformation score, overgrown sole, sole hemorrhage, white line disease

\section{INTRODUCTION}

Lameness is a persistent global health and welfare concern affecting producers and the perception of agriculture by consumers (More et al., 2010). Lameness in dairy cows has been phenotypically associated with reduced milk yield and fertility performance, premature culling, and greater production costs (Leach et al., 2010; Huxley, 2013). Although the cost per lameness case is estimated to range from $€ 178$ to $€ 278$ (Ettema and Østergaard, 2006), herd-prevalence levels of lameness reported internationally range from 24 to $36 \%$ in dairy cows (Leach et al., 2010; Bennett et al., 2014). In addition, current disease knowledge, prevention tools, and proven diagnostics for lameness are generally deemed ineffective by agricultural industry experts (More et al., 2010).

Many international dairy cow breeding programs include lameness or predictor traits of lameness (e.g., hoof lesions and type traits). Nevertheless, genetic improvement for lameness using producer-recorded data is hindered by low heritability (ranging from 0.007 to 0.06 ; Zwald et al., 2004; Pritchard et al., 2013; Abdelsayed et al., 2017), coupled with a lack of data recording (which is necessary to offset the low heritability in the pursuit of high accuracy of selection; Berry et al., 2011). Estimates of the genetic parameters of hoof health traits and linear conformation scores are therefore required 
to determine the potential genetic gain achievable in lameness by using such predictor traits.

The objective of the present study was to advance the scientific knowledge on the genetics of lameness, linear conformation traits, and hoof health traits in dairy cows. The objectives were achieved by estimating genetic parameters for hoof health traits and linear conformation traits in dairy cows and quantifying the genetic relationships among the relevant traits. In addition, the effect of artificially altering hoof health phenotypes (e.g., using a binary vs. a categorical phenotype) on the (co)variance estimates was also quantified; this will be useful to inform the most desirable hoof health phenotypes for consideration in data recording schemes. Finally, we quantified the bias introduced to the variance components for linear conformation traits when these data are not collected from all contemporaries in a herd. Results will be valuable to quantify the gains achievable in reducing the animal-level lameness incidence by optimizing breeding programs.

\section{MATERIALS AND METHODS}

\section{Hoof Health, Mobility, and BCS Data}

As part of a cross-sectional research project, information on mobility scores and BCS were collected during the 2015 calendar year from 11,282 cows in 68 Irish dairy herds; of these, all dairy cows $(\mathrm{n}=7,579)$ residing in 52 of the 68 herds also had hoof health data collected. The aim of the project was to collect hoof health traits from a large sample of cows, representative of the national dairy population, for the estimation of variance components of hoof health for consideration in national genetic evaluations. The average herd size of participating herds was 166 cows, ranging from 45 to 644 cows. Holstein, Jersey, and Friesian breeds represented the main breed for 75,13 , and $9 \%$ of the cows, respectively, which is representative of the national population.

Each herd was visited by trained technicians from Teagasc Moorepark (Fermoy, Ireland) twice during the 2015 calendar year. At each herd visit, conducted in early lactation (i.e., calendar months of March to May, inclusive) and late lactation (i.e., calendar months of June to November, inclusive), each cow present in the herd was assessed for BCS and mobility by 1 of 2 assessors. Body condition score and mobility data were available on 10,651 cows and 10,321 cows from early- and late-lactation herd visits, respectively, in all 68 herds; 9,731 cows were scored at both the early- and latelactation visits. Body condition score was carried out using both visual and tactile appraisal on a scale of 1 to 5 with 0.25 -point increments as described by Edmonson et al. (1989). Mobility scoring was undertaken using the UK Agriculture and Horticulture Development Board 4-point scale (https://dairy.ahdb.org.uk/resources -library/technical-information/health-welfare/mobility -score-instructions/\#.W3SDV7pOlFF; accessed December 16,2017 ), where $0=\operatorname{good}$ mobility (i.e., walks with long strides and an even weight balance on all feet), 1 = imperfect mobility (i.e., walks with shortened strides or uneven steps without an immediately identifiable affected limb), $2=$ impaired mobility (i.e., walks with uneven weight bearing on a limb that is immediately identifiable or walks with obviously shortened strides), and $3=$ severely impaired mobility (i.e., walks with shortened strides, an arched back, and uneven weight balance on all feet).

As part of a separate herd visit, hoof-trimming professionals from one commercial company (Farm Relief Services, Roscrea, Co. Tipperary, Ireland) examined and, where necessary, trimmed both hind feet of each lactating dairy cow in 52 of the 68 herds; a total of 7,579 lactating cows were examined between July 2015 and December 2015. All hoof health traits were recorded by 1 of 2 Teagasc assessors using the International Committee for Animal Recording (ICAR) claw health atlas (ICAR, 2015). Both assessors recorded a similar number of animals and a similar prevalence for each of the hoof health traits, differing by only 4 percentage units on average. The hoof health traits recorded were categorized as overgrown sole $(\mathbf{O G})$, white line disease (WL), sole hemorrhage (SH), sole ulcer, or digital dermatitis. For OG, WL, and SH, the severity of each trait was scored for each digit separately on only the back feet as $0=$ not affected, $1=$ mildly affected, $2=$ moderately affected, and $3=$ severely affected. Sole ulcer was scored as a binary trait (i.e., not affected $=0$, affected $=1$ ) for each digit separately, whereas digital dermatitis was scored as a binary trait (i.e., not affected $=0$, affected $=1$ ) for each hoof (not digit) separately. The digit scores for each trait of OG, WL, and SH were later dichotomized into binary traits based on the presence (i.e., affected $=1$ ) or absence (i.e., not affected $=0$ ) of the ailment. The first dichotomization, which reflected a lax measure of scoring, assumed that digits coded as $\geq 1$ (i.e., mildly, moderately, and severely affected) were deemed affected (i.e., coded as 1); otherwise, digits were categorized as "not affected" (i.e., coded as 0). A second binary trait was derived to mimic data collected if only severely affected cows were scored, and all other cows were assumed not affected; such a situation potentially could occur in reality where hoof-trimmers or farmers themselves recorded the data. This second binary trait, which reflected a more severe definition of scoring, coded only "severely affected" digits (i.e., score 
of 3 ) as affected (i.e., coded as 1), and scores $\leq 2$ (i.e., not affected, mildly affected, and moderately affected) were coded as 0 .

Due to the low trait prevalence, sole ulcer $(1.1 \%$ of digits affected) and digital dermatitis (2.7\% of hooves affected) were excluded from the subsequent analyses. Cows that calved for the first time $<545 \mathrm{~d}$ of age $(\mathrm{n}=4$ cows) or $>1,240 \mathrm{~d}$ of age ( $\mathrm{n}=1 \mathrm{cow})$ were discarded, as were cows that calved $>545 \mathrm{~d}$ from the parity median ( $\mathrm{n}=44$ cows $)$. In addition, records from $\geq 10$ th parity cows $(\mathrm{n}=53$ records) or records from cows calved $>365 \mathrm{~d}$ at data collection $(\mathrm{n}=90$ records) were removed. Moreover, cows that had moved into the herd after January 1, 2015 ( $\mathrm{n}=167$ cows) were also not considered further.

\section{National Lameness Data}

Lameness records, recorded nationally by Irish dairy producers, were available from the Irish Cattle Breeding Federation (ICBF; http://www.icbf.com) database for the years 2012 to 2016, inclusive. The predominant breeds were Holstein, Friesian, and Jersey (78, 16, and $3 \%$ of cows, respectively). Irish dairy producers generally record lameness (i.e., for rear and fore legs) on a per lactation basis as whether or not a cow was visibly lame $(\mathrm{LAME}=1)$ or not visibly lame $(\mathrm{LAME}=0)$, irrespective of whether or not treatment was required or provided. Only one lameness event per cow lactation was considered. Only data from herd-years that had at least 40 calved cows and a minimum lameness prevalence of $5 \%$ were considered in the present study. In addition, only lameness events (i.e., LAME $=0$ or LAME = 1) from cows $<10$ th parity were considered where cows resided in the herd they calved in for at least $300 \mathrm{~d}$ post-calving. A total of 378,524 lameness events (i.e., LAME $=0$ or $\mathrm{LAME}=1$ ) from 307,657 cows in 3,617 herds were available. Cows that calved for the first time $<545 \mathrm{~d}$ of age $(\mathrm{n}=71$ cows $)$ or $>1,240$ $\mathrm{d}$ of age $(\mathrm{n}=941$ cows $)$ were discarded, as were cows that calved $>545 \mathrm{~d}$ from the parity median $(\mathrm{n}=13,181$ cows).

\section{Animal Linear Type Conformation Data}

Trained classifiers routinely score most primiparous cows resident at that time in Irish registered HolsteinFriesian herds for an array of skeletal and mammary linear conformation traits. Producers decide which cows are presented for classification, although it is generally assumed that all eligible primiparous cows are presented for classification. These data were made available to the present study from the ICBF database for calendar years 2006 to 2016, inclusive. A total of 10 conformation traits from 117,859 primiparous cows in 2,076 herds were used in the present study. The linear conformation traits considered in the present study were angularity $(\mathrm{n}=117,859)$, BCS $(\mathrm{n}=78,253)$, chest width $(\mathrm{n}=117,859)$, rump width $(\mathrm{n}=117,859)$, bone quality $(\mathrm{n}=117,859)$, foot angle $(\mathrm{n}=117,859)$, rear legs view from the rear (RLR; $\mathrm{n}=58,049)$, rear legs view from the side $(\mathrm{n}=117,859)$, and locomotion score (LOCO; $\mathrm{n}=117,859)$; the composite trait of feet and legs (FLS; $\mathrm{n}=117,859)$ was also used.

Linear conformation traits are subjectively assessed according to biological extremities, not necessarily optimum scores, and scored on a scale of 1 to 9 , whereas the composite trait of FLS is scored on a scale of 1 (i.e., very poor) to 100 (i.e., excellent). An interpretation of the extreme values for each of the linear type traits is presented in Table 1. Based on the available data, a further trait of whether or not an eligible primiparous cow was presented (CLASSED $=1$ ) or not presented $($ CLASSED $=0)$ for linear classification was derived within herd-calendar year. A calved primiparous cow presented for classification was coded as CLASSED = 1 (117,859 cows). Otherwise, a calved primiparous cow not presented for classification was coded as CLASSED $=0(76,229$ cows $)$, provided the primiparous cow was calved as long, but not longer, than her primiparous contemporaries that were classified. Cows not calved on the day of classification, as well as cows calved after the classified cow that was the fewest days postpartum or cows calved longer than the classified cow that was the longest day postpartum were not considered for the CLASSED trait.

As the majority (i.e., 92\%) of cows presented for classification (i.e., CLASSED = 1) were registered Holstein-Friesian cows, and producers generally do not present nonregistered cows for classification, only registered Holstein-Friesian cows were considered for each of the conformation traits and for the CLASSED trait; as a result, 36,959 records were discarded. Additionally, the present study considered only herd-year records where at least 5 calved primiparous cows were available on the day of classification with a minimum of $40 \%$ of available primiparous cows actually presented for classification; 28,846 records were discarded. Cows calved $<10 \mathrm{~d}$ or $>330 \mathrm{~d}$ on the day of linear scoring ( $\mathrm{n}$ $=34,396$ cows) were omitted from the data set. In addition, primiparous cows that calved for the first time $<545 \mathrm{~d}$ of age or $>1,240 \mathrm{~d}$ of age $(\mathrm{n}=545$ cows $)$ were discarded.

\section{Pedigree}

Pedigree information for each cow was traced back to founder animals where possible, and founder animals 
Table 1. The number of records and cows, the scale and interpretation, and raw mean and standard deviation per trait in the edited data set

\begin{tabular}{|c|c|c|c|c|c|}
\hline Trait & Records, $\mathrm{n}$ & Cows, $\mathrm{n}$ & Scale and interpretation & Mean & $\mathrm{SD}$ \\
\hline Mobility score & 17,481 & 9,385 & 0 (perfect gait) to 3 (severely impaired gait) & 0.43 & 0.61 \\
\hline White line disease & 27,256 & 6,814 & 0 (not affected) to 3 (severely affected) & 0.18 & 0.63 \\
\hline Sole hemorrhage & 27,256 & 6,814 & 0 (not affected) to 3 (severely affected) & 0.22 & 0.66 \\
\hline National lameness records & 71,569 & 57,880 & 0 (not visibly lame) or 1 (visibly lame) & 0.11 & 0.32 \\
\hline $\mathrm{BCS}$ & 53,933 & 53,933 & 1 (very thin) to 9 (very fat) & 4.94 & 1.45 \\
\hline Chest width & 83,798 & 83,798 & 1 (narrow) to 9 (wide) & 5.30 & 1.45 \\
\hline Rump width & 83,798 & 83,798 & 1 (narrow) to 9 (wide) & 5.74 & 1.33 \\
\hline Bone quality & 83,798 & 83,798 & 1 (thick and coarse) to 9 (flat and refined) & 6.77 & 1.22 \\
\hline Foot angle & 83,798 & 83,798 & 1 (very low) to 9 (very steep) & 4.96 & 1.25 \\
\hline Locomotion & 83,798 & 83,798 & 1 (severely impaired gait) to 9 (perfect gait) & 6.08 & 1.10 \\
\hline Rear legs (rear view) & 40,539 & 40,539 & 1 (extreme toe-out) to 9 (parallel feet) & 5.35 & 1.52 \\
\hline
\end{tabular}

were assigned a genetic group based on breed. Only cows with a known sire of a dairy breed (i.e., Friesian, Holstein, Jersey, Montbéliarde, and Norwegian Red) were considered further. Heterosis and recombination loss coefficients, respectively, for each cow were calculated as follows:

$$
1-\sum_{i=1}^{n} \operatorname{sire}_{i} \cdot \operatorname{dam}_{i}
$$

and

$$
1-\sum_{i=1}^{n} \frac{\operatorname{sire}_{i}^{2}+d a m_{i}^{2}}{2}
$$

where sire $_{i}$ and $d a m_{i}$ were the proportion of breed $i$ in the sire and dam, respectively (VanRaden and Sanders, 2003).

\section{Contemporary Groups}

In Irish dairy herds, all cows that calve in close proximity in time to each other are managed similarly. To represent these uniform management structures, contemporary groups, as defined previously by Berry et al. (2013), were derived within herd for each trait separately. An algorithm was used to cluster cows together that calved within $10 \mathrm{~d}$ of each other. Clusters containing $<10$ animals were amalgamated with an adjacent group until the contemporary group contained $\geq 10$ animals, provided the interval between the first and final calving event in the contemporary group did not exceed $90 \mathrm{~d}$. Contemporary groups with $<5$ cows were discarded. For computational reasons, it was not possible to estimate the variance components for producer-scored lameness using the entire remaining data set of 301,712 records. As a result, the number of producer-scored lameness records was reduced; all lameness records from the research study herds $(n=68$ herds) were retained and a random sample of other contemporary groups was selected thereafter. The number of records per trait following all edits is given in Table 1 , and the number of records common among traits is given in Supplemental Table S1 (https://doi.org/10 $.3168 /$ jds.2018-15009).

\section{Statistical Analyses}

Genetic, residual, and, where applicable, permanent environmental variance components in the research study herd data for mobility score and BCS, as well as national lameness records, were undertaken for each trait separately using univariate repeatability animal linear mixed models in ASReml (Gilmour et al., 2009). For the hoof health traits of OG, WL, and SH, both binary (i.e., $0=$ not affected, $1=$ affected) and categorical (i.e., $0=$ not affected, $1=$ mildly affected, $2=$ moderately affected, $3=$ severely affected) dependent variables were fitted for each trait separately using both animal linear mixed models and, where applicable, repeatability animal mixed models in ASReml. For the animal linear mixed models without a permanent environment effect, the sum, the average, and the maximum of all hoof-digit scores per cow were considered as the dependent variables, whereas for the repeatability model, all hoof-digit scores (i.e., 4 scores per cow) were analyzed. Genetic parameters for each conformation 
trait, including CLASSED, were analyzed using univariate animal models. The models fitted were

$$
\begin{aligned}
B C S \text { or } M S & =C G+\text { het }+ \text { rec }+ \text { parity } \mid \text { stage } \\
& + \text { age }+a+c o w+e,
\end{aligned}
$$

Hoof health $1=C G+$ het + rec + parity $\mid$ stage

$$
+ \text { age }+ \text { assessor }+a+e,
$$

Hoof health $2=C G+$ het + rec + parity $\mid$ stage + age

$$
+ \text { assessor }+a+\text { cow }+ \text { leg }+e,
$$

Lame $=C G+$ het + rec + parity $\mid$ age $+a+c o w+e$,

$$
\text { Type }=C G+\text { het }+ \text { rec }+ \text { age }+ \text { stage }+a+e,
$$

where $B C S$ or $M S=$ research study herd trait of BCS or mobility score; Hoof health $1=$ research study herd traits of $\mathrm{OG}, \mathrm{WL}$, and $\mathrm{SH}$ without the inclusion of the animal's permanent environmental effect in the model; Hoof health $2=$ research study herd traits of OG, WL, and SH using the repeatability model; Lame $=$ the binary lameness trait; Type $=$ the assessor-scored conformation traits of angularity, BCS, chest width, rump width, bone quality, foot angle, FLS, RLR, rear legs view from the side, LOCO, or CLASSED (stage was not included when the dependent variable was CLASSED); $C G=$ fixed effect of contemporary group; het $=$ fixed effect of cow's heterosis coefficient (i.e., $0.00,0.01$ to $0.09,0.10$ to $0.19, \ldots, 0.90$ to 0.99 , and $1.00) ;$ rec $=$ fixed effect of cow's recombination loss coefficient (i.e., 0.00 to $0.09,0.10$ to $0.29,0.30$ to 0.49 , and $\geq 0.50)$; stage $=$ fixed effect of $30-\mathrm{d}$ intervals since calving; parity $\mid$ stage $=$ the fixed effect of the interaction between a cow's parity the day after calving (i.e., 1, 2, $3,4,5,>5$ ) and months (i.e., 1 to 12 inclusive) since that cow calved; age $=$ fixed effect of cow age at calving (expressed in months relative to the parity median); parity $\mid$ age $=$ fixed effect of the interaction between a cow's parity the day after calving (i.e., 1, 2, 3, 4, 5, $>5$ ) and the cow's age at calving (expressed in months relative to the parity median); assessor $=$ fixed effect of the person that recorded the trait; $a=$ random additive genetic effect; cow = random effect of the cow's permanent environment; leg $=$ random effect of the leg (i.e., left or right leg) within cow; $e=$ random residual effect. The coefficient of genetic variation was calculated for each trait using methods described by Burdon (2008) to adjust for the bounded nature of the traits. Bivariate sire linear mixed models in ASReml (Gilmour et al., 2009) were used to estimate genetic correlations among the traits of interest; the fitted models were the same as the univariate models.

\section{RESULTS}

Summary statistics including the number of records per trait are given in Table 1. The mean prevalence of digits affected (i.e., number of digits scored $>0$ /number of digits examined) for each of $\mathrm{OG}, \mathrm{WL}$, and $\mathrm{SH}$ were similar, ranging from 18 to $22 \%$ (Table 1). For each of the hoof health traits (OG, WL, and SH), a greater proportion of the lateral digits were affected than the medial digits, irrespective of whether or not the left or right leg (viewed from the rear) was considered; the prevalence ranged from 30 to $41 \%$ in the lateral digits and from 2 to $9 \%$ in the medial digits (Figure 1). In addition, for both OG and WL, a greater proportion of left rear legs $[$ mean $=41 \%(\mathrm{OG})$ and $39 \%(\mathrm{WL})$; SD for $\mathrm{OG}$ and $\mathrm{WL}=0.49]$ were affected than right rear legs $[$ mean $=36 \%(\mathrm{OG})$ and $31 \%(\mathrm{WL})$; SD for $\mathrm{OG}$ and $\mathrm{WL}=0.47]$; there was no difference in the prevalence of affected left rear legs (mean $=49 \%)$ and right rear legs $($ mean $=49 \%)$ for SH (Figure 1$)$.

The distribution of mobility score and BCS for cows in the research study herds are given in Figure 2; based on the average of early- and late-lactation herd visits, $63 \%$ of cows had perfect mobility (i.e., score $=0$ ), whereas $0.65 \%(\mathrm{n}=114)$ of cows were severely impaired (i.e., score $=3)$. There was no difference in the frequency of impaired mobility between the early-lactation herd visits (the mobility of $37 \%$ cows was impaired) and the late-lactation herd visits (the mobility of $38 \%$ cows was impaired). The mean BCS (Figure 2) in early lactation $($ mean $=2.85 ; \mathrm{SD}=2.80)$ was less $(P<0.05)$ than that in late lactation $($ mean $=2.98 ; \mathrm{SD}=2.27)$.

\section{Variance Components}

The heritability of mobility score and BCS in the study herds were $0.07(\mathrm{SE}=0.014)$ and $0.31(\mathrm{SE}=$ $0.023)$, respectively, and the respective repeatability was $0.17(\mathrm{SE}=0.11)$ and $0.50(\mathrm{SE}=0.009)$. The coefficient of genetic variation for mobility score and BCS in the study herds was 9 and $4 \%$, respectively. The mean, genetic standard deviation, and heritability estimates for OG, WL, and SH using the different trait definitions are given in Table 2. Heritability estimates for $\mathrm{OG}, \mathrm{WL}$, and $\mathrm{SH}$ ranged from $0.005(\mathrm{SE}=0.004)$ to $0.17(\mathrm{SE}=0.027)$, from $0.02(\mathrm{SE}=0.004)$ to 0.21 $(\mathrm{SE}=0.030)$, and from $0.03(\mathrm{SE}=0.008)$ to $0.27(\mathrm{SE}$ $=0.032$ ), respectively. The corresponding coefficient of genetic variation ranged from 3 to $40 \%$, from 3 to $45 \%$, and from 6 to $66 \%$ for OG, WL, and SH, respectively. 


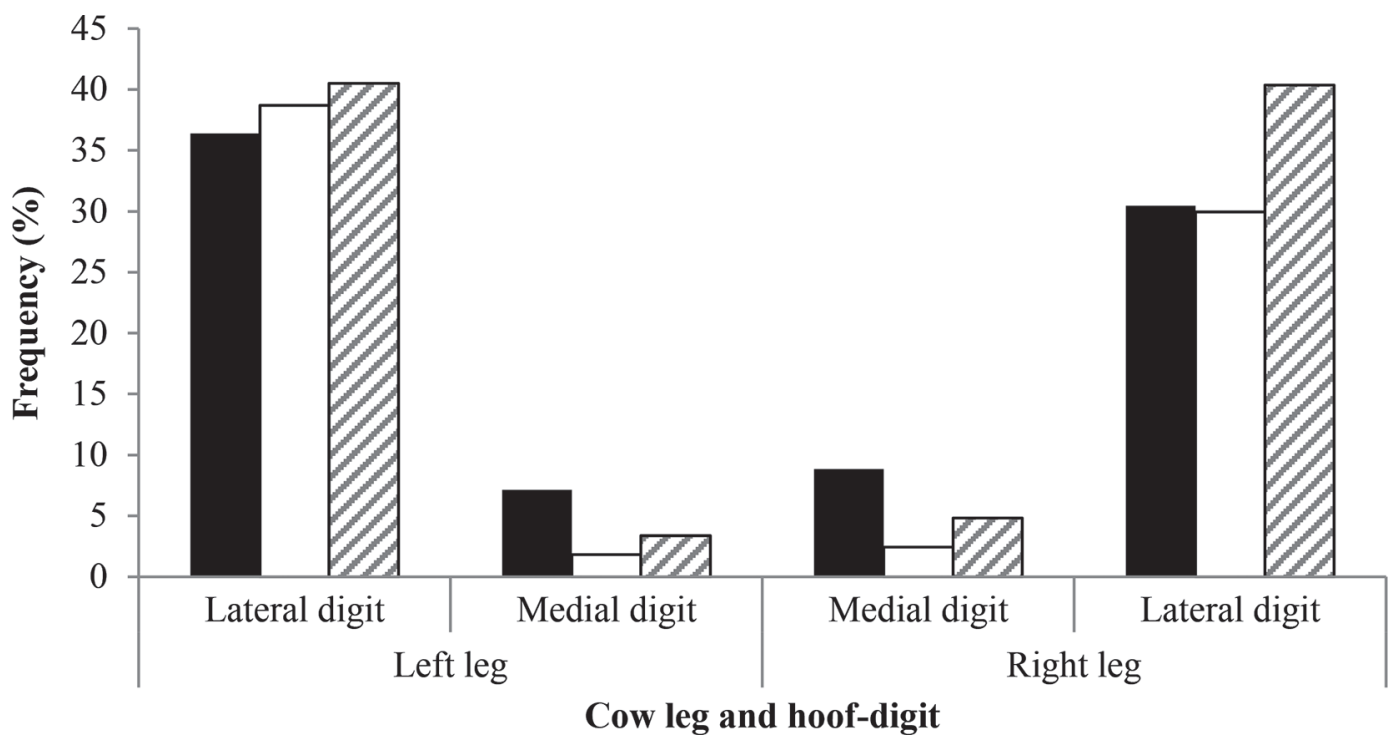

Figure 1. Frequency of hoof scores per cow leg (view from cow rear) and hoof-digit in rear legs of cows that were deemed mildly, moderately, or severely affected by each of the traits overgrown sole (black), white line disease (white) and sole hemorrhage (striped).

The heritability estimates were generally lowest when the repeatability animal model was used. For example, when the dependent variable was on a per digit basis, the heritability estimates for OG ranged from 0.005 to 0.05 , whereas when the dependent variable was collapsed to single score per cow (e.g., the maximum of all 4 digit scores), heritability estimates for OG ranged from 0.01 to 0.17 . Because of the lower heritability estimates when hoof health traits were analyzed on a per digit basis, these traits were not considered in the bivariate analyses. Repeatability for each of the hoof health traits were low, ranging from 0.02 (WL; SE = $0.004)$ to 0.15 (OG; $\mathrm{SE}=0.006)$.

For national producer-scored lameness records, genetic standard deviation, the coefficient of genetic variation, and heritability estimates were $0.05,17 \%$, and $0.03(\mathrm{SE}=0.005)$, respectively. Of the linear conformation traits, heritability estimates (Table 3) were greater for the frame traits (ranging from 0.16 to 0.25 ) than for the feet and leg traits (ranging from 0.05 to 0.10 ). Whether or not a primiparous cow was presented on the day(s) of classification was also under genetic control (heritability $=0.15 ; \mathrm{SE}=0.009$ ); the corresponding genetic standard deviation was 0.15 units.

\section{Correlations Among Study-Herd Traits}

Genetic correlations among the study herd hoof health traits of $\mathrm{OG}, \mathrm{WL}$, and $\mathrm{SH}$ using the various trait definitions investigated were all weakly to moderately positive (ranging from 0.11 to 0.82 ), although not always different from zero $(P>0.05$; Table 4$)$. Ir- respective of the criteria used to define the hoof health traits, the strongest genetic correlations among the hoof health traits were generally between OG and WL, which ranged from 0.17 to 0.82 . The genetic correlation between BCS and mobility score was -0.14 (SE $=0.131)$. Genetic correlations between BCS and the hoof health traits were very weak (ranging from -0.19 to 0.21$)$ and not different from zero $(P>0.05$; Table 4). Nevertheless, cows genetically predisposed to higher BCS tended to be more likely to have higher (i.e., worse) scores for OG (correlations ranged from 0.13 to 0.21 ) yet lower (i.e., better) scores for both WL (correlations ranged from -0.19 to -0.09 ) and $\mathrm{SH}$ (genetic correlation ranged from -0.08 to 0.09 ). Genetic predisposition to higher mobility score (i.e., severely impaired mobility) was moderately to strongly genetically associated $(P<0.05)$ with higher (i.e., worse) scores of $\mathrm{OG}, \mathrm{WL}$, and $\mathrm{SH}$ (correlations ranged from 0.12 to 0.98 ; Table $4)$.

\section{Correlations Among Linear Conformation Traits}

Predisposition to a perfect gait score (i.e., high locomotion score) was both genetically (range: -0.43 to 0.97 ) and phenotypically (range: -0.11 to 0.65 ) correlated with a higher (i.e., better) feet and legs composite score, a steeper foot angle, straighter hind legs (view from the side), and rear toes that pointed directly toward fore toes (Table 3 ). The genetic correlation between the frame traits and the feet and leg traits were weaker than among the frame traits themselves or among the feet and leg traits themselves (Table 3). A 
cow being presented for classification was genetically correlated (range: 0.19 to 0.28 ) with a higher (i.e., better) feet and legs composite score, improved gait score, a steeper foot angle, higher BCS, a wider rump, and a wider chest width (Table 3 ).

\section{Correlations Between Study Herd Traits and Linear Conformation Traits}

Cows genetically predisposed to inferior mobility scores $(P>0.05)$ and higher BCS $(P<0.01)$ were more likely to be presented for linear classification (Table 5). Nevertheless, cows more likely to have a perfect gait score based on linear classification traits and cows more likely to exhibit a higher (i.e., better) feet and legs composite score tended to be more likely to have perfect mobility based on the study herd trait, although the difference was not different from zero (Table 5). Correlations between OG, WL, and $\mathrm{SH}$ with linear conformation traits are provided in Tables 6, 7, and 8, respectively. Genetic correlations between the linear conformation frame traits and the hoof health traits were weak and generally not different from zero, with the exception of the genetic correlations between chest width, rump width, and bone structure with both OG and WL (Tables 6 and 7). Cows genetically predisposed to a wider rump width (correlation range: 0.27 to 0.61 ), a wider chest width (correlation range: 0.19 to 0.41 ), and a more coarse bone structure (correlation range:
-0.50 to -0.03$)$ had a tendency to be more genetically predisposed to OG and WL. The genetic relationship between the hoof health traits and the linear conformation feet and leg traits were also generally weak and not different from zero (Tables 6, 7, and 8), ranging from -0.30 (WL with LOCO) to 0.55 (WL with RLR).

\section{Correlations with Producer-Recorded Lameness}

Cows genetically predisposed to lameness as recorded by producers were also genetically more likely to be affected by $\mathrm{OG}, \mathrm{WL}$, and $\mathrm{SH}$ (correlations up to 0.48 ; Table 9$)$ and to have severely impaired mobility (0.64; $\mathrm{SE}=0.140)$. In addition, cows genetically predisposed to lameness were genetically less likely to be presented for linear classification (although the correlation was not different from zero), to have an inferior gait score, a lower BCS, a poorer feet and legs composite score, as well as, on average, to have rear feet that appeared more parallel when viewed from the rear (Table 5).

\section{DISCUSSION}

Breeding for reduced lameness in cattle contributes to achieving the global objective of a sustainable livestock sector; cows with less lameness incur fewer financial losses (i.e., economically sustainable) and suffer less discomfort and pain, thus contributing to optimal animal welfare standards. Nonetheless, published esti- (a)

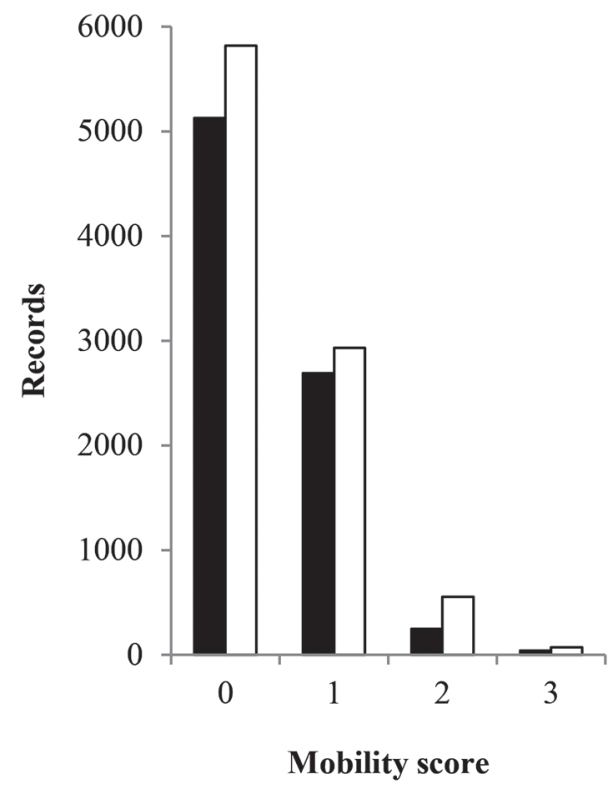

(b)

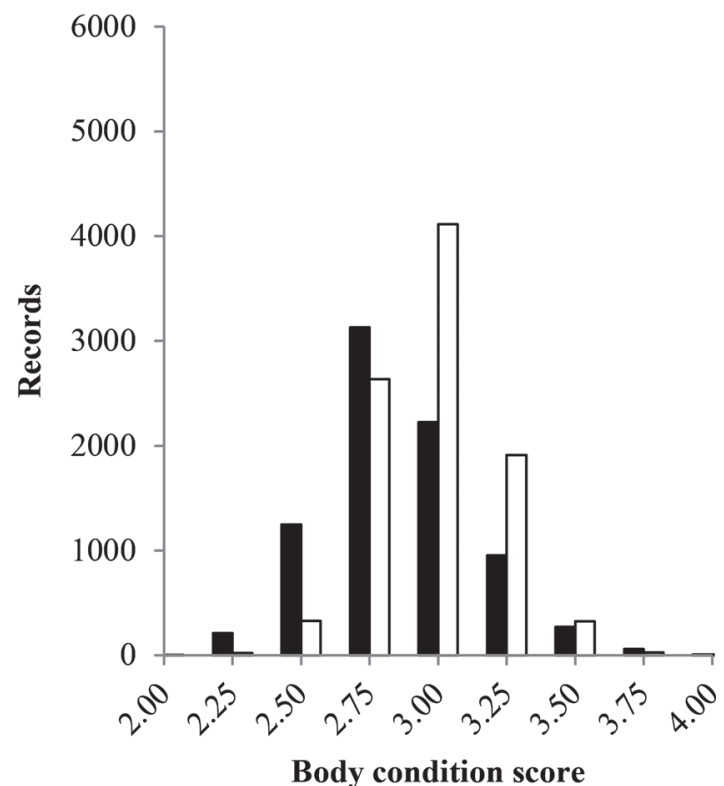

Figure 2. Distribution of (a) mobility scores (scale 0 to 3 ) and (b) BCS (scale 1 to 5 ) for the research study herds ( $\mathrm{n}=68$ ) for scores collected during early-lactation visits (black bars) and late-lactation visits (white bars). 

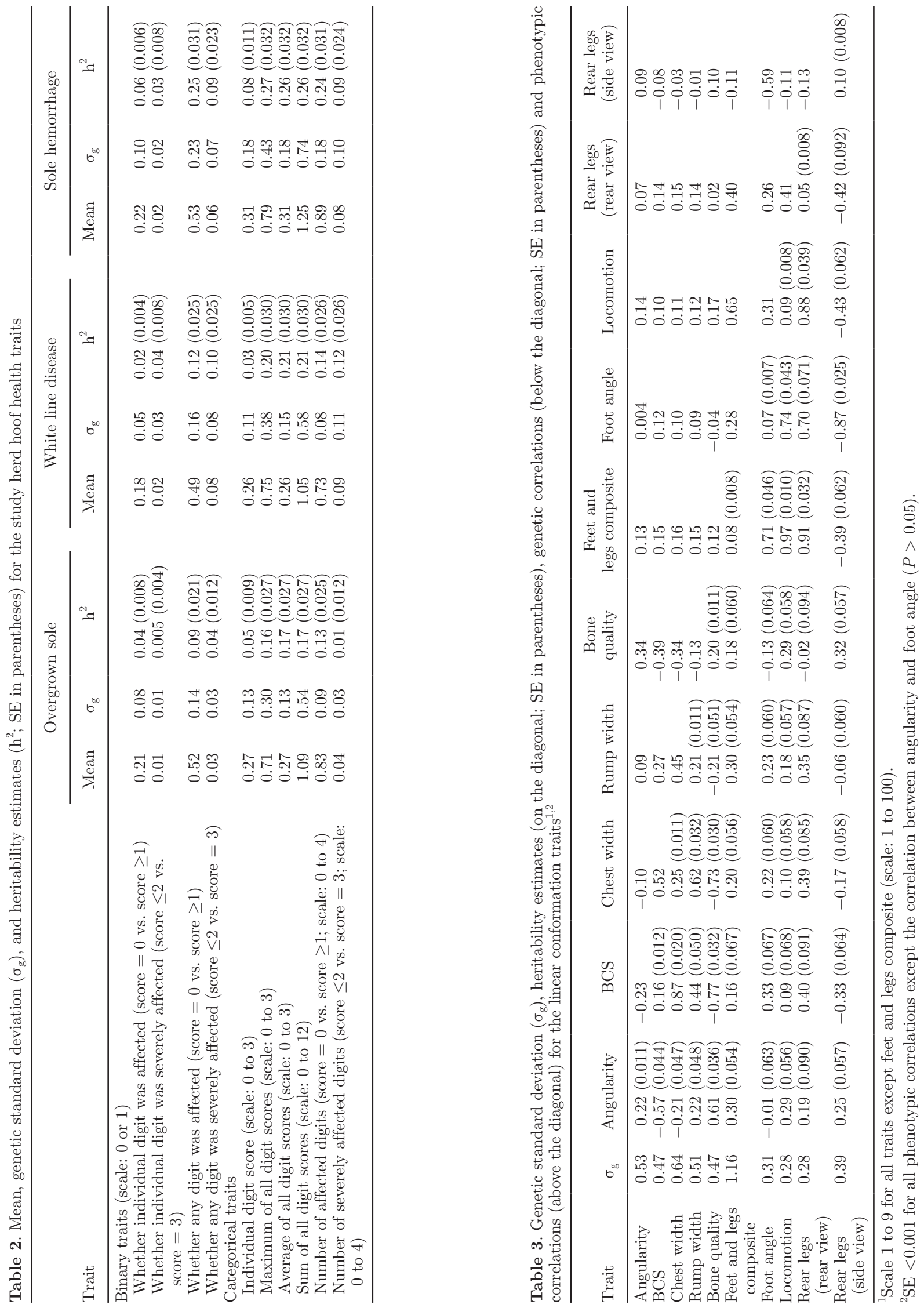


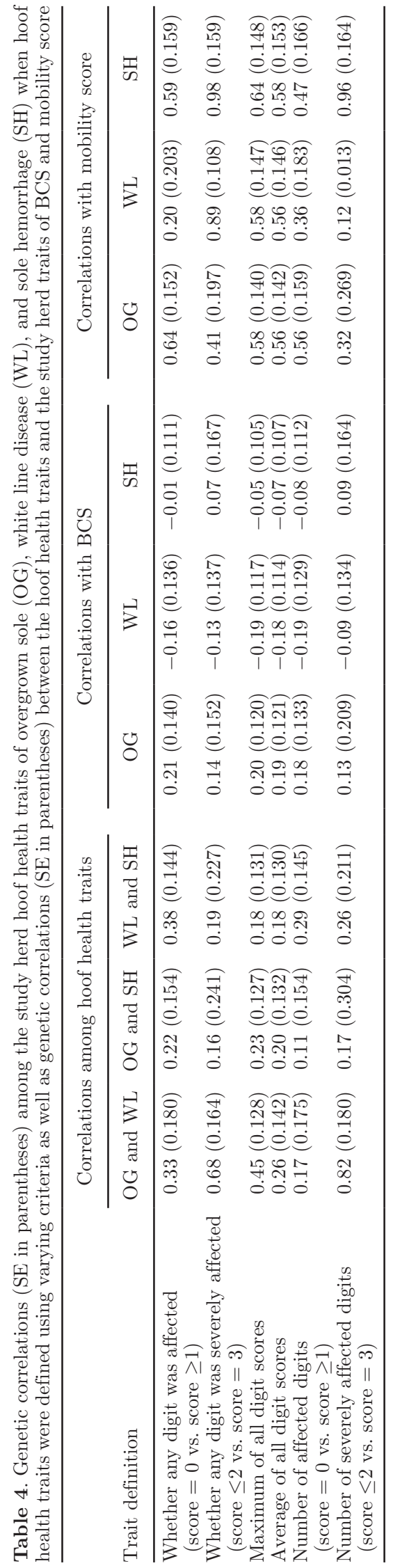

mates on the genetic parameters for lameness in dairy cows using indicator traits of lameness (i.e., hoof health and linear type scores) have generally not investigated the benefits of using alternative definitions to define hoof health traits for genetic analyses of noninfectious hoof disorders.

\section{Hoof Health Traits}

Variance Components. Heritability estimates for the hoof health traits considered in the present study were generally higher than previously reported in other dairy cow populations that also used linear models and considered the same noninfectious and different infectious hoof health traits (van der Waaij et al., 2005; van der Linde et al., 2010; Johansson et al., 2011; van der Spek et al., 2013), the reason for which is likely multifactorial. First, participating herds in the present study were selected because of their reputation for prompt and correct data recording, thus helping to reduce the residual variance. Coupled with this, the effect of pedigree errors on heritability estimates (Van Vleck, 1970) was minimized by verifying the parentage of hooftrimmed cows with genotype data; of the hoof-trimmed cows, $92 \%$ of the cows were genotyped. Moreover, differences in relative economic importance (Enting et al., 1997; Ettema and Østergaard, 2006) and control methods (Leach et al., 2010; Bicalho and Oikonomou, 2013) for hoof health traits exist in different environments and production systems. All herds in the present study were pasture-based, spring-calving production systems; many other studies (Chapinal et al., 2013; Oberbauer et al., 2013; van der Spek et al., 2013) have documented variance components of hoof health traits from cows in confinement, nonseasonal calving herds. Genotype $x$ environment interactions are known to contribute to differences in the genetic variances among production systems, a phenomenon that has been reported for other performance traits in dairy cattle (Berry et al., 2003; Nauta et al., 2006; Haile-Mariam et al., 2008). In addition, differences in trait prevalence among populations may have contributed to the differences in heritability estimates observed in the present study compared with other international reports. To compare heritability estimates for hoof health in the present study with earlier studies, the observed binary-scale heritability estimates, together with the average prevalence in the respective data sets, were transformed to the underlying liability scale using the methods outlined by Robertson and Lerner (1949). For example, some studies reported heritability estimates (on the observed binary scale) for WL ranging from 0.04 (van der Spek et al., 2013 ) to 0.06 (Croué et al., 2017) with a mean data set prevalence of 18 and 14\%, respectively; for comparison 
Table 5. Genetic correlations (SE in parentheses) between the linear conformation traits and whether or not a cow was presented for linear scoring, the study herd traits of BCS and mobility score, and national lameness records

\begin{tabular}{lrrrr}
\hline Trait & $\begin{array}{c}\text { Presented at } \\
\text { linear scoring }\end{array}$ & \multicolumn{1}{c}{ BCS } & Mobility score & \multicolumn{1}{c}{ Lameness } \\
\hline Angularity & $0.20(0.049)$ & $-0.68(0.072)$ & $0.03(0.161)$ & $0.06(0.107)$ \\
BCS & $0.24(0.060)$ & $0.71(0.078)$ & $0.21(0.168)$ & $-0.19(0.117)$ \\
Chest width & $0.22(0.047)$ & $0.59(0.080)$ & $0.08(0.167)$ & $0.12(0.105)$ \\
Rump width & $0.28(0.047)$ & $0.23(0.102)$ & $0.24(0.158)$ & $0.21(0.106)$ \\
Bone quality & $0.01(0.054)$ & $-0.61(0.082)$ & $-0.19(0.161)$ & $-0.11(0.107)$ \\
Foot angle & $0.26(0.062)$ & $0.28(0.118)$ & $-0.16(0.182)$ & $-0.04(0.121)$ \\
Locomotion & $0.21(0.060)$ & $0.06(0.127)$ & $-0.35(0.187)$ & $-0.11(0.119)$ \\
Rear legs (rear view) & $0.18(0.105)$ & $0.07(0.166)$ & $-0.09(0.249)$ & $0.39(0.183)$ \\
Rear legs (side view) & $-0.03(0.063)$ & $-0.40(0.107)$ & $0.09(0.176)$ & $-0.04(0.118)$ \\
Feet and legs composite & $0.19(0.060)$ & $0.14(0.121)$ & $-0.27(0.181)$ & $-0.17(0.111)$ \\
Presented at linear scoring & - & $0.32(0.101)$ & $0.24(0.177)$ & $-0.10(0.112)$ \\
\hline
\end{tabular}

purposes with the present study, we considered the binary trait of whether or not any digit was affected by WL (i.e., score $=0$ vs. score $\geq 1$ ), which had a mean prevalence of $49 \%$ and a heritability estimate (on the observed binary scale) of 0.12 . When the respective heritability estimates were transformed to the underlying scale, heritability estimates were 0.09 (van der Spek et al., 2013) and 0.15 (Croué et al., 2017), making them more in agreement, albeit still lower, than our estimate (0.19). Finally, discrepancies in trait measurement are known to contribute to variability in heritability estimates. For example, Veerkamp et al. (2002) reported differences in heritability estimates (ranging from 0.10 to 0.32 ) among 18 trained classifiers who subjectively scored feet and leg conformation traits on primiparous Holstein cows. In the present study, only 2 scorers, who were trained together at the same time, classified the hoof health traits on all participating cows, thereby ensuring consistent phenotypes. Previous studies on hoof health in cattle (van der Waaij et al., 2005; Chapinal et al., 2013) used data from multiple scorers that may not have maintained consistent scoring, resulting in an inflated residual variance. These hypotheses are further substantiated by the fact that the variance component estimates for producer-recorded lameness derived in the present study were similar to those reported in previous studies (Pritchard et al., 2013; Abdelsayed et al., 2017), which also used producer-recorded data.

Table 6. Genetic correlations (SE in parentheses) between the linear conformation traits and the study herd hoof health trait of overgrown sole

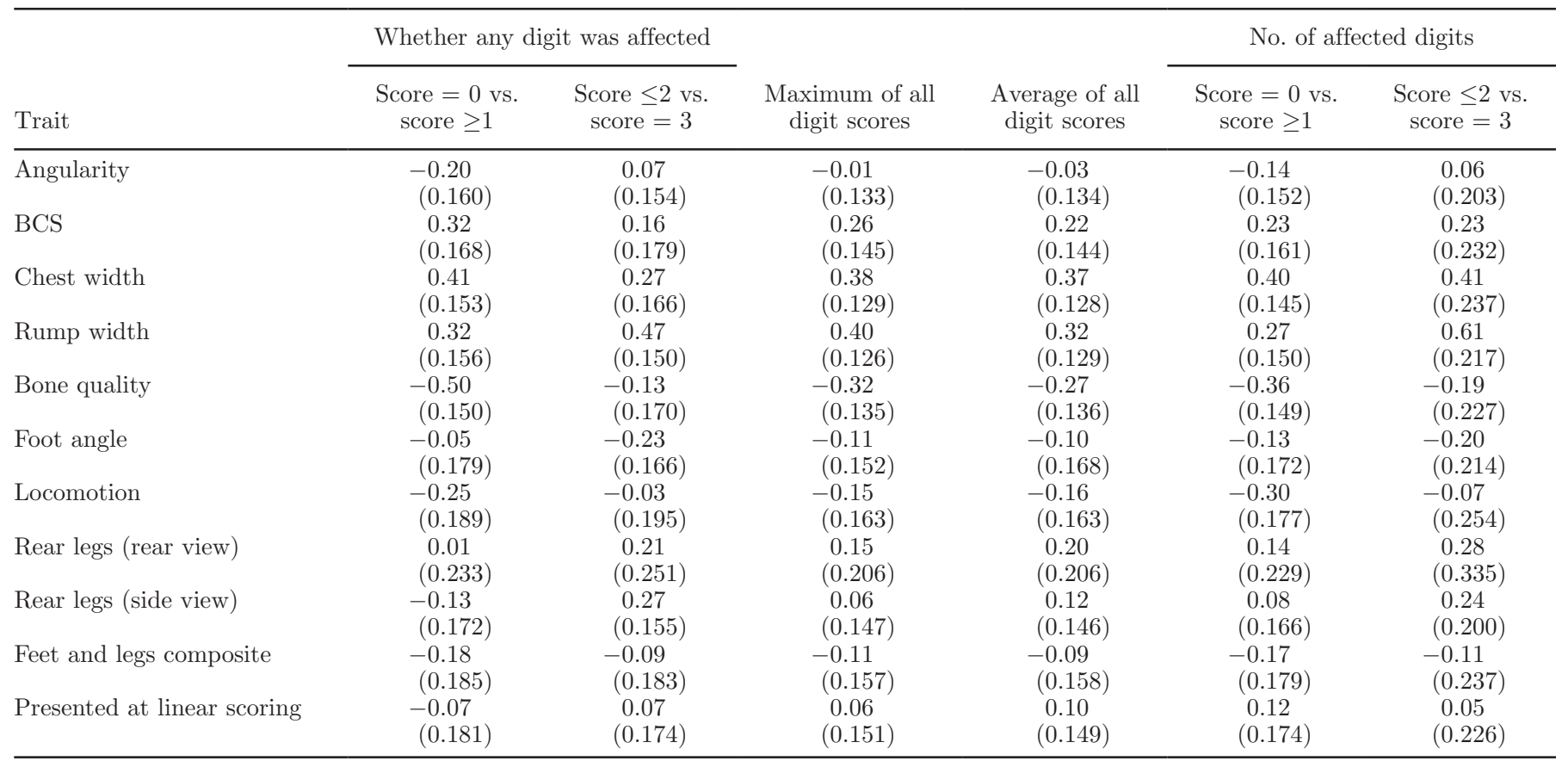


Table 7. Genetic correlations (SE in parentheses) between the linear conformation traits and the study herd hoof health trait of white line disease

\begin{tabular}{|c|c|c|c|c|c|c|}
\hline \multirow[b]{2}{*}{ Trait } & \multicolumn{2}{|c|}{ Whether any digit was affected } & \multirow[b]{2}{*}{$\begin{array}{l}\text { Maximum of } \\
\text { all digit scores }\end{array}$} & \multirow[b]{2}{*}{$\begin{array}{c}\text { Average of all } \\
\text { digit scores }\end{array}$} & \multicolumn{2}{|c|}{ No. of affected digits } \\
\hline & $\begin{array}{l}\text { Score }=0 \text { vs. } \\
\text { score } \geq 1\end{array}$ & $\begin{array}{c}\text { Score } \leq 2 \text { vs. } \\
\text { score }=3\end{array}$ & & & $\begin{array}{l}\text { Score }=0 \text { vs. } \\
\quad \text { score } \geq 1\end{array}$ & $\begin{array}{c}\text { Score } \leq 2 \text { vs. } \\
\text { score }=3\end{array}$ \\
\hline Angularity & $\begin{array}{l}0.05 \\
(0.156)\end{array}$ & $\begin{array}{c}0.21 \\
(0.137)\end{array}$ & $\begin{array}{c}0.14 \\
(0.128)\end{array}$ & $\begin{array}{c}0.18 \\
(0.122)\end{array}$ & $\begin{array}{l}0.17 \\
(0.142)\end{array}$ & $\begin{array}{c}0.21 \\
(0.132)\end{array}$ \\
\hline $\mathrm{BCS}$ & $\begin{array}{c}0.07 \\
(0.170)\end{array}$ & $\begin{array}{l}-0.04 \\
(0.155)\end{array}$ & $\begin{array}{l}0.02 \\
(0.144)\end{array}$ & $\begin{array}{c}0.06 \\
(0.139)\end{array}$ & $\begin{array}{c}0.10 \\
(0.160)\end{array}$ & $\begin{array}{l}-0.02 \\
(0.151)\end{array}$ \\
\hline Chest width & $\begin{array}{c}0.21 \\
(0.161)\end{array}$ & $\begin{array}{c}0.19 \\
(0.144)\end{array}$ & $\begin{array}{c}0.22 \\
(0.132)\end{array}$ & $\begin{array}{c}0.23 \\
(0.127)\end{array}$ & $\begin{array}{c}0.23 \\
(0.149)\end{array}$ & $\begin{array}{c}0.19 \\
(0.139)\end{array}$ \\
\hline Rump width & $\begin{array}{c}0.35 \\
(0.156)\end{array}$ & $\begin{array}{c}0.47 \\
(0.130)\end{array}$ & $\begin{array}{c}0.43 \\
(0.123)\end{array}$ & $\begin{array}{l}0.35 \\
(0.121)\end{array}$ & $\begin{array}{l}0.29 \\
(0.146)\end{array}$ & $\begin{array}{c}0.41 \\
(0.129)\end{array}$ \\
\hline Bone quality & $\begin{array}{l}-0.19 \\
(0.160)\end{array}$ & $\begin{array}{l}-0.04 \\
(0.146)\end{array}$ & $\begin{array}{l}-0.17 \\
(0.134)\end{array}$ & $\begin{array}{l}-0.18 \\
(0.129)\end{array}$ & $\begin{array}{l}-0.20 \\
(0.149)\end{array}$ & $\begin{array}{l}-0.03 \\
(0.142)\end{array}$ \\
\hline Foot angle & $\begin{array}{l}-0.07 \\
(0.192)\end{array}$ & $\begin{array}{c}0.24 \\
(0.179)\end{array}$ & $\begin{array}{l}0.15 \\
(0.152)\end{array}$ & $\begin{array}{l}0.09 \\
(0.164)\end{array}$ & $\begin{array}{l}0.04 \\
(0.170)\end{array}$ & $\begin{array}{c}0.19 \\
(0.177)\end{array}$ \\
\hline Locomotion & $\begin{array}{l}-0.30 \\
(0.184)\end{array}$ & $\begin{array}{l}0.29 \\
(0.164)\end{array}$ & $\begin{array}{l}0.06 \\
(0.163)\end{array}$ & $\begin{array}{l}-0.01 \\
(0.157)\end{array}$ & $\begin{array}{l}-0.22 \\
(0.175)\end{array}$ & $\begin{array}{l}0.19 \\
(0.166)\end{array}$ \\
\hline Rear legs (rear view) & $\begin{array}{c}0.04 \\
(0.239)\end{array}$ & $\begin{array}{c}0.55 \\
(0.188)\end{array}$ & $\begin{array}{c}0.35 \\
(0.199)\end{array}$ & $\begin{array}{c}0.28 \\
(0.196)\end{array}$ & $\begin{array}{c}0.10 \\
(0.227)\end{array}$ & $\begin{array}{c}0.45 \\
(0.20)\end{array}$ \\
\hline Rear legs (side view) & $\begin{array}{l}-0.02 \\
(0.173)\end{array}$ & $\begin{array}{r}-0.01 \\
(0.156)\end{array}$ & $\begin{array}{l}-0.04 \\
(0.146)\end{array}$ & $\begin{array}{l}-0.04 \\
(0.141)\end{array}$ & $\begin{array}{l}-0.06 \\
(0.163)\end{array}$ & $\begin{array}{c}0.02 \\
(0.153)\end{array}$ \\
\hline Feet and legs composite & $\begin{array}{r}-0.17 \\
(0.184)\end{array}$ & $\begin{array}{l}0.36 \\
(0.154)\end{array}$ & $\begin{array}{c}0.14 \\
(0.155)\end{array}$ & $\begin{array}{c}0.06 \\
(0.150)\end{array}$ & $\begin{array}{r}-0.14 \\
(0.169)\end{array}$ & $\begin{array}{l}0.27 \\
(0.157)\end{array}$ \\
\hline Presented at linear scoring & $\begin{array}{r}-0.06 \\
(0.181)\end{array}$ & $\begin{array}{c}0.29 \\
(0.152)\end{array}$ & $\begin{array}{l}0.06 \\
(0.147)\end{array}$ & $\begin{array}{l}0.06 \\
(0.140)\end{array}$ & $\begin{array}{c}0.12 \\
(0.168)\end{array}$ & $\begin{array}{l}0.23 \\
(0.149)\end{array}$ \\
\hline
\end{tabular}

Trait Definition. Phenotype collection for health traits can be costly, particularly when measurements are not routinely generated on all "eligible" animals (e.g., hoof health phenotypes on entire herds). Therefore, to maximize genetic gain and recover the costs of data procurement, it is imperative that the data collected are as informative as possible. If the dairy industry wants to reduce the incidence of all affected hoof digits (i.e., considering mildly, moderately, and severely affected digits as affected) then, based on results from

Table 8. Genetic correlations (SE in parentheses) between the linear conformation traits and the study herd hoof health trait of sole hemorrhage

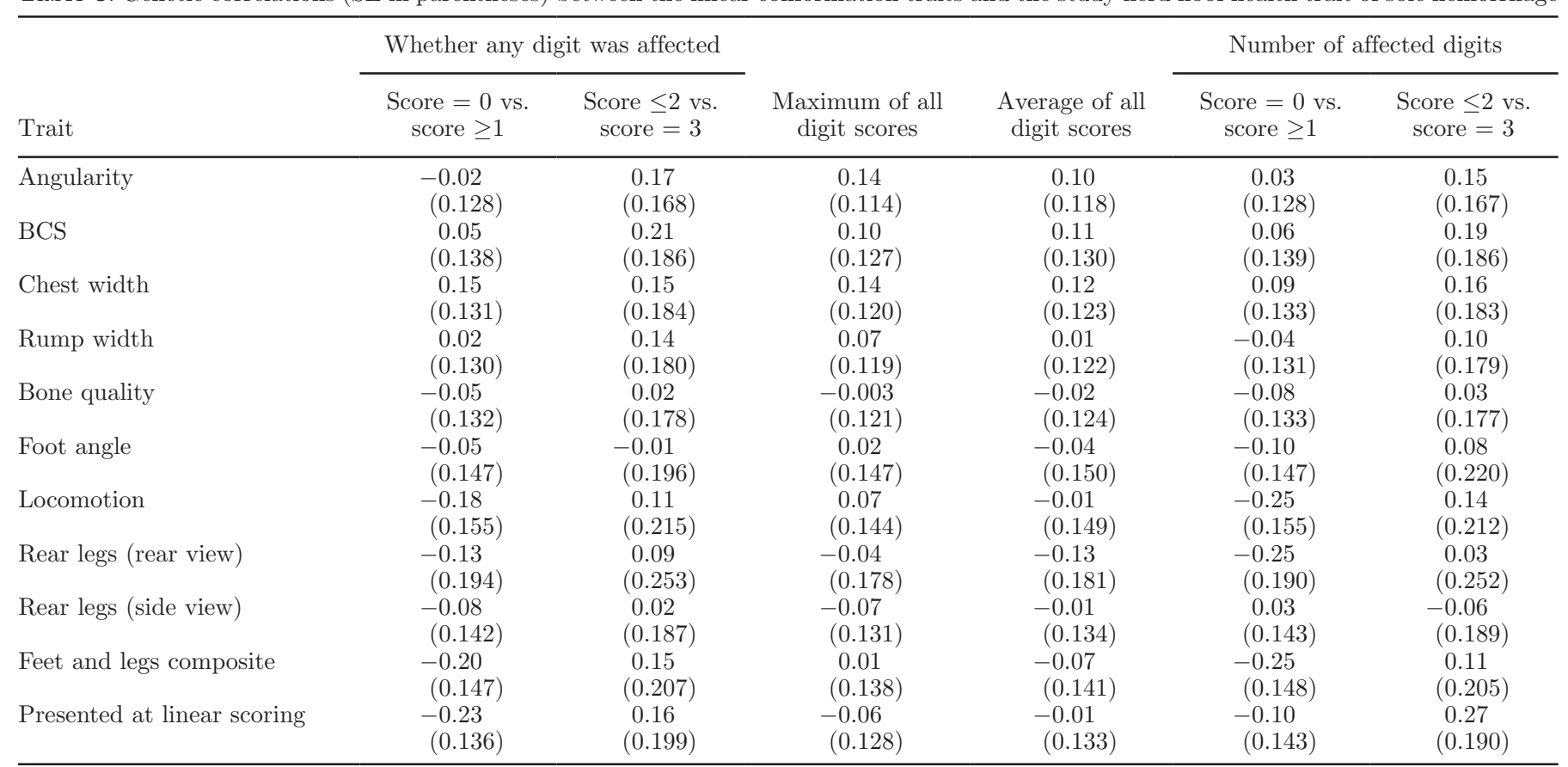


the present study, phenotype observations pertaining to an animal's average score of all hoof digits would yield the greatest benefit when data are limited (i.e., large genetic variation as well as high heritability; thus, high reliability). Otherwise, if the industry intends to penalize only severely affected animals in the breeding population, phenotype measurements pertaining to an animal's maximum score of all hoof digits may be optimum (i.e., large genetic variation as well as high heritability and thus high reliability). In the present study, because trait definitions that considered each hoof digit separately within the same analysis yielded smaller variance components, their benefit to breeding programs is limited.

In the present study and elsewhere (Thomsen and Baadsgaard, 2006), assessors had clearly defined cutoff thresholds for assigning the scores of categorical traits (i.e., $0=$ not affected, $1=$ mildly affected, $2=$ moderately affected, and $3=$ severely affected). Therefore, it is not surprising that the coefficient of genetic variation did not change largely when score thresholds were dichotomized to reflect differences in biological extremities. Nevertheless, this may not reflect data collected by assessors in large-scale breeding programs. For example, if many assessors (or producers) were requested to categorize hoof health as binary traits (i.e., coded as 0 or 1), it is likely that some assessors would code only severely affected digits as one but all other digits as zero. That said, other assessors may record both moderately and severely affected digits as affected (i.e., score $=1$ ), whereas mildly and unaffected digits may be coded as zero. This notion may be especially true as herd size increases and more than one assessor records the data in a given herd. To test the effect of this, categorical digit scores for OG were dichotomized; $50 \%$ of not affected digits and $50 \%$ of mildly affected digits were randomly coded as 0 , and the remaining $50 \%$ of not affected and $50 \%$ of mildly affected digits were randomly coded as 1 ; all moderately and severely affected digits were still coded as 1 . The resulting heritability estimate decreased from 0.09 (i.e., where $0=$ all unaffected digits, 1 = all mildly, moderately, and se- verely affected digits) to 0.03 because of an increase in residual variance. Such discrepancies between assessor measurement techniques increase the number of records required to yield accurate genetic evaluations. Moreover, greater genetic variation existed in the present study for categorical traits compared with the binary traits; greater genetic variation also contributes to faster genetic gain. Artificially dichotomizing (i.e., where 0 $=$ all not affected digits, $1=$ all mildly, moderately, and severely affected digits) the hoof health traits in the present study resulted in a loss of 2 to $12 \%$ and 2 to $6 \%$ of information (i.e., 1 - genetic correlation ${ }^{2}$ ) in contrast to the categorical traits of the average and maximum score of digits, respectively. For these reasons, breeding programs should seek to collect categorical trait data rather than binary data, because cut-off thresholds on the categorical scale may be easier to interpret by the assessor, resulting in reduced residual variance and a requirement for fewer records for the same accuracy of selection. That said, it is important that extension support material is available to assessors that clearly describes the appropriate classification for each phenotype category.

\section{Bias in Presentation of Cows for Linear Conformation Scoring}

Of herds that presented primiparous cows for conformation scoring in the present study, only $76 \%$ of the primiparous Holstein cows were actually presented for scoring. Selected cows were genetically inclined to having superior locomotion, superior feet and leg composite scores, a lower lameness prevalence, and a higher BCS. These results indicate that, in general and not unexpectedly, cows with desirable attributes are more likely to be presented for classification. The bias in presentation of cows for linear scoring will bias the genetic evaluations because the selection decision of whether or not a cow was presented for conformation scoring has not been considered in the genetic evaluations. To avoid bias, breeding organizations could consider whether a cow was presented for conformation scoring

Table 9. Genetic correlations (SE in parentheses) between the study herd hoof health and national lameness records when the hoof health traits were defined using varying criteria

\begin{tabular}{|c|c|c|c|}
\hline Trait definition & Overgrown sole & White line disease & Sole hemorrhage \\
\hline Whether any digit was severely affected ( & $0.42(0.186)$ & $0.18(0.179)$ & $0.01(0.226)$ \\
\hline Maximum of all digit scores & $0.41(0.153)$ & $0.38(0.161)$ & $0.27(0.146)$ \\
\hline Number of affected digits (score $=0$ vs. score $\geq 1$ ) & $0.21(0.187)$ & $0.48(0.169)$ & $0.21(0.161)$ \\
\hline Number of severely affected digits ( score $\leq 2$ vs. score $=3$ ) & $0.39(0.247)$ & $0.19(0.173)$ & $0.03(0.226)$ \\
\hline
\end{tabular}


(i.e., CLASSED $=0$ or CLASSED $=1$ ) when deriving breeding values for conformation traits or else ensure that all contemporaries are presented for scoring.

\section{Future Direction of Breeding Programs}

The detailed phenotype measurements of hoof health traits collected from a relatively small number of animals in the present study (compared with international studies) yielded considerably higher heritability estimates than previous studies. From these results, we can conclude that data generated from a carefully selected representative sample of the population may contribute to faster genetic gain (i.e., higher heritability trait thus achieving high accuracy of selection despite a smaller population size) than traditional data collection methods. Some countries (e.g., Australia; Pryce et al., 2017) are considering strategies that limit reference populations for genomic selection to cows from just a selection of herds that have both genotyped and well-phenotyped cattle. The higher heritability estimates expected from such populations (as in the present study) contribute to the need for fewer animals to achieve the same accuracy of selection (Daetwyler et al., 2008).

As with most health traits, published heritability estimates for lameness are generally lower when producer-recorded data are used (Pritchard et al., 2013; Abdelsayed et al., 2017). This poses questions regarding the quality and completeness of producer-recorded data and whether it is optimal for use in national breeding programs. Results from the present study substantiate that producer-recorded data are useful in breeding programs as the data collected were positively correlated with that of the phenotypes derived from the trained personnel who scored hoof health traits and the (different) trained personnel who scored linear conformation traits.

\section{CONCLUSIONS}

Results from the present study suggest that genetic selection for either improved hoof health or cow mobility score should result in a reduction in animal-level incidence of lameness. Irrespective of the phenotype used to define $\mathrm{OG}$, WL, or $\mathrm{SH}$, considerable exploitable genetic variation exists for each trait, indicating that breeding programs can make considerable genetic gain. Results also suggest that the primiparous Holstein cows that are presented for linear classification in Ireland represent only cows with the most desirable attributes; this has ramifications for achieving unbiased genetic evaluations. In all, the results described herein can be used to inform breeding programs targeting improvements in hoof health.

\section{ACKNOWLEDGMENTS}

Funding from the Irish Department of Agriculture, Food and the Marine STIMULUS research grant HealthyGenes is greatly appreciated.

\section{REFERENCES}

Abdelsayed, M., M. Haile-Mariam, and J. E. Pryce. 2017. Genetic parameters for health traits using data collected from genomic information nucleus herds. J. Dairy Sci. 100:9643-9655. https:// doi.org/10.3168/jds.2017-12960.

Bennett, R. M., Z. E. Barker, D. C. J. Main, H. R. Whay, and K. A. Leach. 2014. Investigating the value dairy farmers place on a reduction of lameness in their herds using a willingness to pay approach. Vet. J. 199:72-75. https://doi.org/10.1016/j.tvjl.2013.09 .068 .

Berry, D. P., M. L. Bermingham, M. Good, and S. J. More. 2011. Genetics of animal health and disease in cattle. Ir. Vet. J. 64:5. https: //doi.org/10.1186/2046-0481-64-5.

Berry, D. P., F. Buckley, P. Dillon, R. D. Evans, M. Rath, and R. F Veerkamp. 2003. Estimation of genotype $\times$ environment interactions, in a grass-based system, for milk yield, body condition score, and body weight using random regression models. Livest. Prod. Sci. 83:191-203. https://doi.org/10.1016/S0301-6226(03)00098-8.

Berry, D. P., J. F. Kearney, K. Twomey, and R. D. Evans. 2013. Genetics of reproductive performance in seasonal calving dairy cattle production systems. Ir. J. Agric. Food Res. 52:1-16.

Bicalho, R. C., and G. Oikonomou. 2013. Control and prevention of lameness associated with claw lesions in dairy cows. Livest. Sci. 156:96-105. https://doi.org/10.1016/j.livsci.2013.06.007.

Burdon, R. D. 2008. Short note: Coefficients of variation in variables with bounded scales. Silvae Genet. 57:179-180.

Chapinal, N., A. Koeck, A. Sewalem, D. F. Kelton, S. Mason, G. Cramer, and F. Miglior. 2013. Genetic parameters for hoof lesions and their relationship with feet and leg traits in Canadian Holstein cows. J. Dairy Sci. 96:2596-2604. https://doi.org/10.3168/jds.2012 -6071 .

Croué, I., F. Fikse, K. Johansson, E. Carlén, G. Thomas, H. Leclerc, and V. Ducrocq. 2017. Genetic evaluation of claw health traits accounting for potential preselection of cows to be trimmed. J. Dairy Sci. 100:8197-8204. https://doi.org/10.3168/jds.2017-13002.

Daetwyler, H. D., B. Villanueva, and J. A. Woolliams. 2008. Accuracy of predicting the genetic risk of disease using a genome-wide approach. PLoS One 3:e3395. https://doi.org/10.1371/journal.pone .0003395 .

Edmonson, A. J., I. J. Lean, L. D. Weaver, T. Farver, and G. Webster. 1989. A body condition scoring chart for Holstein dairy cows. J. Dairy Sci. 72:68-78. https://doi.org/10.3168/jds.S0022 -0302(89)79081-0.

Enting, H., D. Kooij, A. A. Dijkhuizen, R. B. M. Huirne, and E. N. Noordhuizen-Stassen. 1997. Economic losses due to clinical lameness in dairy cattle. Livest. Prod. Sci. 49:259-267. https://doi.org/ 10.1016/S0301-6226(97)00051-1.

Ettema, J. F., and S. Østergaard. 2006. Economic decision making on prevention and control of clinical lameness in Danish dairy herds. Livest. Sci. 102:92-106. https://doi.org/10.1016/j.livprodsci.2005 .11 .021 .

Gilmour, A. R., B. Gogel, B. Cullis, R. Thompson, and D. Butler. 2009. ASReml user guide release 3.0, VSN International Ltd. Hemel Hempstead, UK.

Haile-Mariam, M., M. J. Carrick, and M. E. Goddard. 2008. Genotype by environment interaction for fertility, survival, and milk production traits in Australian dairy cattle. J. Dairy Sci. 91:4840-4853. https://doi.org/10.3168/jds.2008-1084.

Huxley, J. 2013. Impact of lameness and claw lesions in cows on health and production. Livest. Sci. 156:64-70. https://doi.org/10.1016/j .livsci.2013.06.012. 
ICAR (International Committee for Animal Recording). 2015. ICAR claw health atlas. Accessed Sept. 20, 2017. http://www.icar.org/ documents/icar_claw_health_atlas.pdf.

Johansson, K., J.-Å. Eriksson, U. S. Nielsen, J. Pösö, and G. P. Aamand. 2011. Genetic evaluation of claw health in Denmark, Finland and Sweden. Interbull Bull. 44:224-228.

Leach, K. A., H. R. Whay, C. M. Maggs, Z. E. Barker, E. S. Paul, A. K. Bell, and D. C. J. Main. 2010. Working towards a reduction in cattle lameness: 1 . Understanding barriers to lameness control on dairy farms. Res. Vet. Sci. 89:311-317. https://doi.org/10.1016/j .rvsc.2010.02.014

More, S. J., K. McKenzie, J. O'Flaherty, M. L. Doherty, A. R. Cromie, and M. J. Magan. 2010. Setting priorities for non-regulatory animal health in Ireland: results from an expert Policy Delphi study and a farmer priority identification survey. Prev. Vet. Med. 95:198-207. https://doi.org/10.1016/j.prevetmed.2010.04.011.

Nauta, W. J., R. F. Veerkamp, E. W. Brascamp, and H. Bovenhuis. 2006. Genotype by environment interaction for milk production traits between organic and conventional dairy cattle production in the Netherlands. J. Dairy Sci. 89:2729-2737. https://doi.org/10 .3168/jds.S0022-0302(06)72349-9.

Oberbauer, A. M., S. L. Berry, J. M. Belanger, R. M. McGoldrick, J. M. Pinos-Rodriquez, and T. R. Famula. 2013. Determining the heritable component of dairy cattle foot lesions. J. Dairy Sci. 96:605-613. https://doi.org/10.3168/jds.2012-5485.

Pritchard, T., M. Coffey, R. Mrode, and E. Wall. 2013. Genetic parameters for production, health, fertility and longevity traits in dairy cows. Animal 7:34-46. https://doi.org/10.1017/ S1751731112001401.

Pryce, J. E., P. Douglas, C. M. Reich, A. J. Chamberlain, P. J. Bowman, T. T. T. Nguyen, B. A. Mason, C. P. Prowse-Wilkins, G. J. Nieuwhof, T. Hancock, M. Shaffer, and B. J. Hayes. 2017. Reliabilities of Australian dairy genomic breeding values increase through the addition of genotyped females with excellent phenotypes. Proc. Assoc. Advmt. Anim. Breed. Genet. 22:133-136.
Robertson, A., and I. M. Lerner. 1949. The heritability of all-or-none traits: Viability of poultry. Genetics 34:395-411.

Thomsen, P. T., and N. P. Baadsgaard. 2006. Intra-and inter-observer agreement of a protocol for clinical examination of dairy cows. Prev. Vet. Med. 75:133-139. https://doi.org/10.1016/j.prevetmed 2006.02.004.

van der Linde, C., G. De Jong, E. P. C. Koenen, and H. Eding. 2010 Claw health index for Dutch dairy cattle based on claw trimming and conformation data. J. Dairy Sci. 93:4883-4891. https://doi .org/10.3168/jds.2010-3183.

van der Spek, D., J. A. M. Van Arendonk, A. A. A. Vallée, and H. Bovenhuis. 2013. Genetic parameters for claw disorders and the effect of preselecting cows for trimming. J. Dairy Sci. 96:6070-6078. https://doi.org/10.3168/jds.2013-6833.

van der Waaij, E. H., M. Holzhauer, E. Ellen, C. Kamphuis, and G. De Jong. 2005. Genetic parameters for claw disorders in Dutch dairy cattle and correlations with conformation traits. J. Dairy Sci 88:3672-3678. https://doi.org/10.3168/jds.S0022-0302(05)73053 $-8$.

Van Vleck, L. D. 1970. Misidentification in estimating the paternal sib correlation. J. Dairy Sci. 53:1469-1474. https://doi.org/10.3168/ jds.S0022-0302(70)86416-5.

VanRaden, P. M., and A. H. Sanders. 2003. Economic merit of crossbred and purebred US dairy cattle. J. Dairy Sci. 86:1036-1044. https://doi.org/10.3168/jds.S0022-0302(03)73687-X

Veerkamp, R. F., C. L. M. Gerritsen, E. P. C. Koenen, A. Hamoen, and G. De Jong. 2002. Evaluation of classifiers that score linear type traits and body condition score using common sires. J. Dairy Sci. 85:976-983. https://doi.org/10.3168/jds.S0022-0302(02)74157 $-\mathrm{X}$.

Zwald, N. R., K. A. Weigel, Y. M. Chang, R. D. Welper, and J. S. Clay. 2004. Genetic selection for health traits using producerrecorded data. I. Incidence rates, heritability estimates, and sire breeding values. J. Dairy Sci. 87:4287-4294. https://doi.org/10 .3168/jds.S0022-0302(04)73573-0. 